\title{
CUTANEOUS REACTION AND DESENSITIZATION IN QUININ IDIOSYNCRASY *
}

JOHN J. O'MALLEY, M.D.

Lieutenant-Commander, M. C., U. S. Navy

AND

DeWAYNE G. RICHEY, M.D.

Lieutenant, M. C., U. S. Naval Reserve Force

WASHINGTON, D. C.

The purpose of this communication is to add two new cases of idiosyncrasy to quinin to the long list of such instances encountered in the literature, with an allusion to a skin reaction and attempts at densensitization.

CAse 1.-G. V. W., male, chief yeoman, aged 22 years, was admitted to the U. S. Naval Hospital, Washington, D. C., as a case of influenza. His illness pursued a typical course and in two weeks he had recovered completely. During the latter days of his convalescence elixir of iron, quinin and strychnin were prescribed for him in 4 mil doses. Within fifteen minutes after the first dose was administered, the eyes began to smart and itch. There was some photophobia and lacrimation. Soon the face, neck, chest and hands became a "lobster red" color, which rapidly became a generalized erythema. This was attended by an intense pruritus. There was a certain degree of headache, puffiness of the eyelids and muscae volitantes, but no vertigo nor tinnitus aurium were noticed. Some dyspnea and epigastric burning were encountered. The erythema and pruritus completely disappeared in two and one-half hours.

On questioning the patient, it was learned that during childhood quinin was frequently taken for coryzal attacks on which occasions no untoward symptoms occurred. Not until eight years ago was any reaction from this drug noticed, when an attack, similar to the one just described, followed the ingestion of approximately $0.2 \mathrm{gm}$. of quinin. The second attack occurred one year later, when a similar dose was taken. From this time on until two years ago, the patient on several occasions took tablets containing, in addition to other ingredients, $0.065 \mathrm{gm}$. of quinin. No ill effects were noticed from these until October, 1917, when, after taking one tablet, a syndrome was caused, characterized by erythema, pruritus, edema, headache, vertigo, tinnitus, muscae volitantes, dyspnea, nausea and vomiting. Since 1917 the patient has not taken quinin in any form until his admission to the Naval Hospital.

$\mathrm{He}$ says he can eat eggs, cucumbers, strawberries, tomatoes, buckwheat and all types of sea food with impunity. He never had hay fever or horse asthma. Typhoid or smallpox vaccine did not occasion any undue reaction.

His past, family and personal history reveal no noteworthy features Physical examination is negative.

CASE 2.-Captain S., U. S. Marine Corps, male, aged 28 years, married was admitted to the U. S. Naval Hospital, Washington, D. C., complaining of tenderness, weakness, loss of weight and stiffness in the legs and thighs There was no cough and repeated physical examinations and thoracic roentgenograms failed to reveal any tuberculous process. The patient had returned

* Published by permission of the Surgeon-General, U. S. Navy.

* From the U. S. Nava! Medical School and U. S. Naval Hospital. 
on sick leave from eighteen months duty in San Domingo, where, since early in March, 1918, he had experienced three definite attacks of benign tertian malaria. The first two attacks were three months apart-in March and June, 1918. They were clinically typical and responded readily to $1 \mathrm{gm}$. of quinin sulphate, three times a day. On both occasions absolutely no untoward effects were caused by the quinin, nor had the patient ever had cinchonism prior to this time, despite the fact that he had taken $1 \mathrm{gm}$. of quinin a day as a prophylactic ten years previously while on an engineering expedition in South America. In December, 1918, a third attack of malaria was experienced. As in the previous two attacks, he had distinct chills, forty-eight hours apart, and the plasmodium viva.r was found in the blood smear. Quinin therapy was instituted. The first dose, $1 \mathrm{gm}$. of quinin sulphate, produced no ill effects. The second dose of the same size, given a few hours later, caused a blotchy, diffuse rash, generalized pruritus, headache, timnitus aurium, muscae volitantes, photophobia, lacrimation, dyspnea, epigastric flushes of heat, nausea and diarrhea. This attack persisted for several hours. Therefore the drug was discontinued for two days and then given subcutaneously, once a day. Each injection was attended by a syndrome similar to the first though milder. Having apparently recovered from malaria, the patient returned to this country.

Except for an attack of amebic dysentery in 1913, his health has always been good. Has never had any hay fever, horse asthma nor any reactions to the various fruits, vegetables, sea food or drugs other than quinin.

It would appear from an analysis of these cases that the hypersensitiveness to quinin was acquired. In neither case could a similar familial tendency be elicitetd. The clinical manifestations were extremely suggestive of cinchonism, and it was found that neither individual reacted with any of the other common drugs where idiosyncrasies are known to occur. Furthermore, it was found that the tolerance of Case 1 was somewhat less than $0.03 \mathrm{gm}$. when given by mouth, and that of Case 2 was about $0.25 \mathrm{gm}$. when given by mouth or intravenously in a 5 per cent. solution. Both men failed to react clinically with the other alkaloids of cinchona, whereas the various salts of quinin produced a reaction in sufficient dosages.

After the method of Boerner, ${ }^{1}$ shin reactions were tried in both cases. Two superficial abrasions were made with a sterile needle on the flexor surface of the forearm, about 3 inches apart, after the parts were cleansed with 95 per cent. ethyl alcohol and dried. To one was applied quinin bisulphate $(1: 10)$ while the other was left untouched, functioning as a control. We were able to confirm Boerner's findings in that the scarification to which the quinin antigen had been applied showed a marked reaction in both men, while the control merely exhibited the results of the traumatism. The reactions began with an itching, smarting or burning sensation from four to five minutes after application. This was quickly followed by an area of edema on either side of the needle scratch. This edematous area was, as a rule, irregular in outline and reached its height in from fifteen or twenty minutes to one hour. It was surrounded by a bright red halo of erythema, which

1. Boerner, F., Jr.: J. A. M. A. 68:907 (March 24) 1917. 
varied from 3 to $5 \mathrm{~cm}$. in diameter. An identical reaction could be produced by the use of the chlorhydrosulphate or dihydrochlorid of quinin in 1:20 dilutions. Control tests, as shown in Figure 1, of salicylic acid (10 per cent.), caffein citrate ( 10 per cent.), potassium iodid (saturated solution), atropin sulphate ( 0.5 per cent.) and epinephrin $(1: 1,000)$ failed to provoke analogous reactions in either patient.

Later, additional controls were made, using cinchonin sulphate, and cinchonidin sulphate as antigens. No reactions were encountered with these alkaloids of cinchona, whereas the quinin yielded the usual intense response.

Twelve individuals were selected who were known not to be hypersensitive to the drug. All were given as much as $2 \mathrm{gm}$. of quinin sulphate a day without manifesting any discomfiture. The cutaneous tests in all these men were negative. As Boerner indicated, there is reason to believe that the reaction is specific to those who are hypersensitive to quinin, and, also, it has been found that these two patients failed to respond to other idiosyncrasy-producing drugs, even to certain other alkaloids of cinchona.

An attempt was now made to desensitize the patients to quinin. The procedure described by Heran and Saint Girons ${ }^{2}$ gave brilliant results in Case 1, while the tolerance in Case 2 was increased from 0.25 to 0.7 $\mathrm{gm}$. The method, briefly, consisted in giving by mouth a "desensitizing dose" of $0.005 \mathrm{gm}$. with $0.5 \mathrm{gm}$. of sodium bicarbonate. In one hour and thirty minutes, $0.1 \mathrm{gm}$. of quinin bisulphate and $0.5 \mathrm{gm}$. of sodium bicarbonate were ingested in cachets. The "desensitizing dose" remained constant each day, while, in the second dose, the amount of quinin was increased $0.1 \mathrm{gm}$. each day. The quantity of sodium bicarbonate remained the same. Only one dose was given in any one day. It was found that, except for the "desensitizing dose" on the first day, Case 1 showed no untoward symptoms. At the end of the eleventh day, $2 \mathrm{gm}$. were being taken without any disagreeable symptoms. Case 2 did not respond so readily, and it was necessary to discontinue the procedure when $0.7 \mathrm{gm}$. was taken on account of a diarrhea and some visual disturbances. It is of interest to note that the degree of intensity of the skin reaction was in inverse ratio to the amount of quinin ingested without ill effect. In Case 1 the cutaneous reaction gradually became less marked, until on the tenth day it completely disappeared. The reaction in Case 2 became gradually less distinct until 0.7 gm. was given, but when the toxic symptoms manifested themselves there was efflorescence which simulated in intensity that encountered in the initial tests.

2. Heran and St. Girons: Montpellier med. 39:21. 669, 1917. 
Two other methods of desensitization were instituted in Case 2. One was the administration of quinin bisulphate, by mouth, in increasing doses once a day. The initial dose was $0.03 \mathrm{gm}$. and it was increased by as much each day. The other method consisted in giving a "desensitizing dose" of $0.01 \mathrm{gm}$. quinin chlorhydrosulphate in 5 mils of sterile water, intravenously, and, after from thirty to forty-five minutes, giving a second dose starting with $0.2 \mathrm{gm}$. of the same drug and increasing $0.1 \mathrm{gm}$. a day. By both methods $0.7 \mathrm{gm}$. could be given with safety, but symptoms appeared if larger quantities were administered.

We are not prepared to offer a theory as to the nature of these reactions in terms of anaphylaxis or allergy. Many investigators, adherent to either the humoral or cellular theories of anaphylaxis, agree that a protein must be associated with its provocation, while others maintain that proteins are not necessary. If it were true that a protein must be involved in the production of anaphylaxis, idiosyncrasies and skin reactions to various alkaloids, which are not proteins, would seek explanation on some other basis. Several authors, notably Zieler" and Pöhlmann, ${ }^{4}$ have placed these phenomena in the realm of intoxications rather than manifestations of anaphylaxis, basing their conclusions, for the most part, on the inability to produce passive sensitization in animals with the sera of hypersensitive persons. On the other hand, Klaussner $^{5}$ and Bruck $^{6}$ report passive sensitization in guinea-pigs by injecting the sera of individuals with idiosyncrasies to drugs.

Hans Meyer has evolved a theory that there is an alteration in the calcium content of the tissues, while, on the other hand, Pepper and Krumbhaar ${ }^{7}$ deny that there is a deficiency in calcium metabolism in edema and urticaria. Hunt ${ }^{8}$ and Lewis ${ }^{9}$ have shown that a certain percentage of cases of poison susceptibility can be influenced by diet.

Kolmer, ${ }^{10}$ who has had a vast experience with skin reactions, refers to them as "anaphylactic or pseudo-anaphylactic." He states that there is not sufficient data at hand to prove that the mechanism of the local or skin anaphylactic reaction is identical with that of the general or fatal reaction following intravenous injections. He, as well as Longcope, ${ }^{11}$ admits that examples of drug anaphylaxis, unless such drugs contain protein substances, offer certain difficulties as to explanation,

3. Zieler: München. med. Wchnschr. 59:401, 1641, 1912.

4. Pöhlmann: München. med. Wchnschr. 61:543, 1914.

5. Klaussner: München. med. Wchnschr. 57:1451, 1983, 1910; 58:138, 1911.

6. Bruck: Berl. klin. Wchnschr. 47:517, 1928, 1910.

7. Pepper, W., and Krumbhaar, E. B.: J. Infect. Dis. 14:476, 1917.

8. Hunt, R.: U. S. P. H. and M. H. S. Hyg. Lab. Bull. 69: 1910.

9. Lewis, J. H.: J. A. M. A. 72:329 (Feb. 1) 1919.

10. Kolmer, J. A.: Infection, Immunity and Spec. Ther., 1917, p. 617; Bull. Johns Hopkins Hosp. 28:163 (May) 1917.

11. Longscope, W. T.: Am. J. M. Sc. 152:6125 (Nor.) 1916. 
but maintains that a drug may be capable of sensitizing body cells in the same manner, as in the "indirect anaphylaxis" of Richet, or that a new protein compound is formed in the patient's serum to which he may be "actively sensitized."

\section{SUMMARY}

In the two cases of idiosyncrasy to quinin, the skin test descsibed by Boerner has been found a good index to hypersensitiveness.

2. These cases reacted to various salts of quinin only, failing to respond to cinchonin, cinchonidin, salicylic acid, caffein citrate, potassium iodid, atropin sulphate and epinephrin.

3. A method of desensitization described by Heran and Saint Girons proved efficacious in one case and increased the tolerance in another.

4. The intensity of the cutaneous reaction was found to be in inverse ratio to the degree of desensitization obtained. ${ }^{12}$

12. Lutz, W.: Cor.-B1. f. schweiz. Aerzte 47:1601 (Dec. 1) 1917. Sollmann, T.: J. Pharmacol \& Exper. Therap. 9:309 (March) 1917. Strickler, A.: New York M. J. 104:198 (July 29) 1916. Zinnser: Infection and Resistance, 1919, p. 410 . 


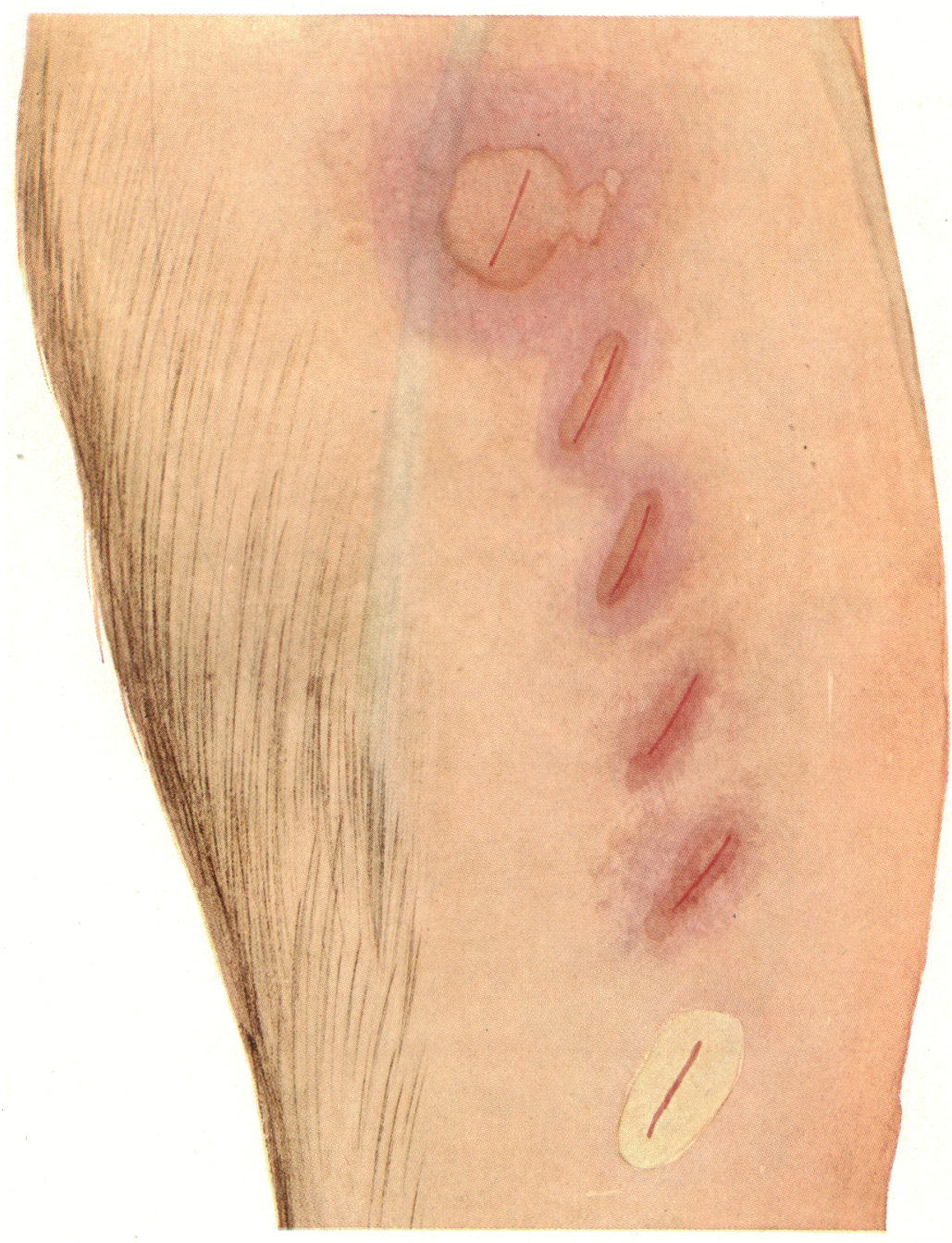

From above downward the drugs employed were quinin bisulphate (1:10), salicylic acid (10 per cent.), caffein citrate (10 per cent.), potassium iodid (saturated solution), atropin sulphate $(0.5$ per cent.) and epinephrin $(1: 1,000)$.

Illustrating Article by John J. O'Malley, M.D., and DeWayne G. Richey, M.D., Archives of Internal Medicine, October, 1919 